\title{
Neuroscience and Sex/Gender
}

\author{
Isabelle Dussauge • Anelis Kaiser
}

Received: 4 September 2012 / Accepted: 13 September 2012 / Published online: 2 October 2012

(C) Springer Science+Business Media Dordrecht 2012

This special issue publishes interdisciplinary scholarship which aims to map and re-imagine the relations between neuroscience and gender studies.

\section{neuroGenderings: The Network}

The authors of the present special issue were all participants in the workshop neuroGenderings: Critical Studies of the Sexed Brain (Uppsala, 2010). Then coorganizers, now guest editors, we work in gender studies, neuroscience, and science and technology studies. In 2010, we did not know for a fact that the neuroGenderings initiative would grow and develop into an international network and conference series. Now we know.

In neuroGenderings, a transdisciplinary and international group of researchers from the neurosciences, the humanities and science studies working on and in the neuroscience of gender convened to discuss the broad theme of sex/gender and the brain. As this specific interdisciplinary field of research usually

I. Dussauge $(\bowtie)$

Center for Gender Research, University of Uppsala, Uppsala, Sweden

e-mail: isabelle.dussauge@gender.uu.se

\section{A. Kaiser}

Center for Cognitive Science, Institute of Computer Science and Social Research, University of Freiburg,

Freiburg, Germany

e-mail: anelis.kaiser@cognition.uni-freiburg.de hosts very different epistemological approaches, a common knowledge of neuroscience and gender studies was a prerequisite for the group's theoretical and methodological exchange. The participants lively debated crucial issues, from current research on sex/gender difference in neuropsychology, through the implications of notions of sex/gender, gender identity and sexuality used in neuroscientific experimentation, to the social workings of a sexed/gendered brain.

More precisely, the neuroGenderings workshop achieved an impressive first mapping of the research on sex/gender in neurosciences and the methodological frames used in those sciences. We discussed, for instance, the role assigned to "sexed" regions of the brain, by analyzing the relevance of the notion of sexual dimorphism, itself a system of significance that is always and solely framed by neuro-logical sexual dichotomy. Further, we elaborated on what kind of sex/gender facts, results, and understandings of the brain dominate in neurosciences and how neuroscientific facts about sex/ gender are produced. We recapitulated how neuro-sex/ gender-facts are dependent on our contemporary historical and political context and we discussed some of the ethical and political consequences of neuroscientific knowledge production about sex/gender and sexuality. Not least, neuroGenderings explored the workings of neurosexism without dismissing neuroscience altogether. Neurosexism is a term launched by psychologist Cordelia Fine [1], and it stands for the (mis)use of neuroscientific facts and factoids [2] to assert that women and men are categorically 
different by virtue of their brains, or to simply rehash available sex/gender stereotypes with the vocabulary of the brain.

Like neuroGenderings, this special issue brings attention to the imbalance within neuroscience between a dominant neuroscience of sex/gender difference and a less visible neuroscience of gender ambiguity and sex/gender similarities. The present publications also reflect the epistemic emergences coming from the empirical results of new brain imaging techniques such as fMRI, for instance the paths from raw data to sexed/ gendered brain images, in relation to the methods and statistics mobilized during the process of investigation.

\section{Related Critical Projects}

Of course, neuroGenderings does not stand alone. The recent years have been marked by attempts to define productive critical engagements with neuroscience. Especially two attempts have received quite some attention in neuroethical contexts: critical neuroscience [3] launched in the journal BioSocieties, and neuroskepticism [4] made visible, in print, in $A J O B$ Neuroscience.

However, the invisibility of gender-and other power orderings usually addressed in feminist studies, such as sexuality or race-is striking in this ongoing establishment of critical engagements with the "neuro" in interdisciplinary settings. This is true even of the scholarly events dominated by the humanities and social sciences, such as the symposia organized by the seminal ENSN. The lack of a feminist voice in these critical initiatives is, in the long-term, hugely detrimental to the objectives of achieving a scholarly counterweight to the threatening scenario of an unreflexively triumphant neuroscience. A newer and more constructive alternative is the visionary "Neurocultures Manifesto" [5] which calls for critical feminist biocultural engagements with neuroscience and proposes central tenets for that purpose. Pitts-Taylor's Neurocultures Manifesto talks in many ways to the directions mapped out here.

\section{Sex and Gender}

As an interdisciplinary research network, neuroGenderings deals with a great diversity not only in methods but also in terminology. And because terminology is intrinsically intertwined with the object of examination it is, to us, of primary relevance that we keep clarifying the notions of sex and gender in the context of neuroscience. The editors and most of the authors represented here share the perspective that there does not exist a given, clear-cut distinction between "sex" and "gender" (e.g. [6, 7]) and that what culturally passes as sex is indeed already gender. In the neurosciences too, it is becoming increasingly evident that the biological and social components of a gendered brain function or structure cannot be separated. Therefore feminist neuroscientists are still working to define an appropriate vocabulary for what is not inseparable but interlaced, not fixed but alterable. In the meantime we do not want to dismiss "sex" altogether (see also [8]), particularly since our research field is inside the natural sciences or in interaction with them. This is why we refer mostly to "sex/gender" [9] in this introduction.

\section{Generative Directions}

The absence of feminist voices in these most visible critical-ethical debates on neuroscience calls for different simultaneous directions. The neuroGenderings encounters made visible the intellectual contours of the frontline critical research in the emerging field of neuroscience of/and gender. Alongside with previously published work (e.g. [1, 10-12]), the articles in the present special issue make three ongoing trends on that frontline salient:

1. The proposal of a feminist and gender sensitive neuroscience

A specifically feminist critical position is needed which conducts neuroscience on the basis of insights, perspectives and reflexivity from gender studies and feminist theory. Feminist approaches, for instance from gender/queer studies or feminist STS, are necessary for the implementation of scientifically sounder notions of sex/gender, sexuality and power in neuroscientific experiments. For instance, postmodern theories of sex/gender such as queer theory have been deconstructing gender and have proposed theories of gender as performative for twenty years now [6]. Can gender-as-performative be used in a neuroscientific experiment in order to 
study gendered practices as embodied in the brain, and what could such a neuroscientific experiment look like? Moreover, what can we retain from the gender-studies based critics of a compulsory binary gender order in our analyses of sexually dimorphic aspects of the brain? Within this direction, a longterm goal for feminist neuroscientists is to elaborate a new conceptual approach to the relation between sex/gender and the brain, one that could help to head neuroscientists and gender theorists to an innovative interdisciplinary place, far away from social and biological determinisms but still engaging with the materiality of the brain.

In this issue, neurobiologist and gender studies scholar Deboleena Roy addresses neuroethics' limited engagement with difference and proposes directions for a neuroscience informed by gender sciences. Roy argues that the question of difference is a deeply ethical one. Roy calls for a revalorisation of (neuro)biological complexity and proposes that the neuroscientific studies of difference ought not to just reproduce pre-given categories of gender, but instead multiply difference and investigate difference "in and of itself". What does, indeed, a difference in e.g. humor tell us about how people live their lives, and about the inscription of power into our bodies and brains? Roy also suggests that neuroscience devotes more attention to the mutual relation between brain structure and function, and therefore the neural workings of power.

In her present article, biologist and gender studies scholar Katrin Nikoleyczik uses Karen Barad's agential realist framework to define "transdisciplinary diffractive strategies" for the integration of gender scientific concepts and perspectives into neurosciences. Nikoleyczik first identifies an irreducible difference in objects of knowledge: Whereas much scholarship in biology/neurosciences addresses sex/ gender as a material, individual property (gender-1), much research in the social and cultural sciences addresses gender as a social phenomenon outside the individual (gender2), distinct from sex and individual biology. Nikoleyczik goes on to propose methodological directions for how neuroscience could work informed by perspectives and concepts from gender studies' and social sciences, and for how gender science could engage more closely with biological notions of sex.

2. The proposal of alternative accounts of the brain from outside the neurosciences.

Secondly, a more radical critical position is also required which does not seek consensus, bridging or communication between the social sciences and the neurosciences with the purpose of improving the neurosciences. Rather, a position is crucially needed now which retains the legitimacy to be critical of neuroscience's cultural status, its underlying historical project, its financial advantage over social sciences, or its taking over of the objects of knowledge of the cultural and social sciences. Perspectives presented in neuroGenderings delineated such a feminist position which acknowledges and brings to the surface the political struggles and stakes of the neurosciences. The direction offered by such a position is the production of other goals, and other constructive-critical standpoints about the human and about the brain, than those of the neurosciences.

In her article, philosopher and gender studies scholar Cynthia Kraus defines such a position and proposes a focus on studies of political conflicts and scientific controversies. Kraus analyses two examples: The non-controversial embracing by feminists of the notion of brain plasticity; and the controversial issue of brain sex and gender identity in the intersex movement. Kraus's stance is that we need to give the analysis of political conflicts analytical precedence over that of scientific controversies: The shifting texture of social conflicts is what makes public scientific controversies possible. Consequently, Kraus argues for a scholarly position which makes lines of social conflict visible rather than assuaging conflicts between scientific disciplines.

Gender scientist, biologist and science studies scholar Sigrid Schmitz offers a critical analysis of the gendered notions deployed in neuroeconomics. Schmitz argues that the neurosciences of decision-making build on and reproduce stereotypical sexing/gendering and hierarchization of reason and emotion. Schmitz links this problematic gendering of rationality/ emotionality to other ethically problematic issues of meritocracy, neuro-enhancement, and what she coins the "new neuro-determinism": 
the belief that an exact knowledge of the material state of the brain would make possible the prediction of behavior.

Science studies and media scholar Hannah Fitsch interrogates the historical and sociological status of neuroimages. Fitsch explores the conventions of imaging, not so much to criticize the reductionism at work as to emphasize the productive side of that reductionism, i.e. to identifiy which material reality imaging technologies are able to describe. Drawing on philosopher Jacques Rancière's work, Fitsch argues that at the core of the aesthetics of images there is always ethics, since the act of making visible and the choices of invisibilization are always deeply political.

In turn, social psychologist Cordelia Fine addresses how neuroscientific claims about sex/gender directly affect and gender our lives. Fine shows how the deeply embedded cultural conviction of "hardwired" sex/gender differences in the brain has consequences for everyday behavior and for people's minds. By reviewing research on gender stereotypes, Fine pinpoints their self-fulfilling influence on social perception, self-perception and individual behavior in experimental as well as mundane settings. The permanent short-term activation of gender stereotypes in everyday life, the reinforcement of the neuroscientists' and media's lack of interest in identifying gender bias or changing the status quo as well as their willingness to accept prescriptive social norms are, to Fine, some of the consequences that overinflated claims about brain sex differences can have on our minds.

3. The review of the claims and evidential grounds of neuroscientific facts and factoids concerning gender

The work of reviewing and clarifying the field of the neurosciences of gender is coextensive with and, in many ways, foundational of the two directions above. Two larger works by Cordelia Fine [1] and Rebecca Jordan-Young [12] have recently examined large regions of the even larger landscapes of the neuroscience of sex/gender differences and its popularizations. Through these meticulous reviews of hundreds of the most central publications in neuroscience, both authors concluded that the neurosciences do not have satisfactory evidence that the brains of women and men are unalterably different in behaviorally relevant ways.

In the present issue, neurobiologist Catherine Vidal reviews common misbeliefs in/about the neurosciences of sex/gender differences. By focusing on research on language, mathematics or risk-taking, Vidal demonstrates how the assumption that women and men are biologically bound to difference implies the reproduction of gender stereotypes in experimental settings. Vidal proposes that the plasticity of the brain enables us to account for the more serious observations of neural differences. Vidal also considers the role of the media in disseminating the results of dubious studies, and advocates deeper public information about the neuroscience of sex/gender understood through the lenses of brain plasticity.

Finally, epidemiologist and gender scientist Rebecca Jordan-Young and neuroscientist Raffaella Rumiati have authored a piece about the neuroscientific research paradigm of "hardwired" sex/gender, i.e. the prevailing assumption that there are fundamental sex differences in the organization of the brain that would depend on prenatal hormonal exposure. Jordan-Young and Rumiati offer a selective review of neuroscientific work and explain why the hardwired paradigm is both unscientific and unethical. Subsequently, and illustrating that the task of critical review is related to the definition of new scientific agendas, JordanYoung and Rumiati propose an alternative neuroscientific account of sex/gender differences, grounded in an acknowledgment of the variability and plasticity of brain and behavior.

As this special issue is being published in print, a third international neuroGenderings meeting is in preparation. These three directions of work are ongoing, growing and defining new agendas both in and outside the neurosciences.

\section{References}

1. Fine, Cordelia. 2010. Delusions of gender: How our minds, society, and neurosexism create difference/The real science behind sex differences. New York: W. W. Norton/Icon. 
2. Dussauge, Isabelle. 2012. Factoids of gender, brains and science. Lecture, Uppsala University, 29 August 2012.

3. Choudhury, Suparna, Saskia Kathi Nagel, and Jan Slaby. 2009. Critical neuroscience: Linking neuroscience and society through critical practice. BioSocieties 4(1): 61-77.

4. Marks, Jonathan. 2010. A neuroskeptic's guide to neuroethics and national security. AJOB Neuroscience 1(2): 4-12.

5. Pitts-Taylor, Victoria. 2012. Neurocultures Manifesto. Social Text: Periscope. http://www.socialtextjournal.org/ periscope/2012/04/neurocultures-manifesto.php. Accessed 19 September 2012.

6. Butler, Judith. 1990. Gender trouble: Feminism and the subversion of identity. London: Routledge.

7. Butler, Judith. 1993. Bodies that matter: On the discursive limits of sex, 1st ed. London: Routledge.
8. Haraway, Donna. 1991. Simians, cyborgs, and women: The reinvention of nature. New York, NJ: Routledge, and London: Free Association Books.

9. Kaiser, Anelis. 2012. Re-conceptualizing sex and gender in the human brain. Topical issue, "Sex and gender differences revisited - new perspectives and new findings". Journal of Psychology 220(2): 130-136.

10. Kaiser, Anelis, Sven Haller, Sigrid Schmitz, and Cordula Nitsch. 2009. On sex/gender related similarities and differences in fMRI language research. Brain Research Reviews 61: 49-59.

11. Dussauge, Isabelle, and Anelis Kaiser. 2012. Re-queering the brain. In Neurofeminism: Issues at the intersection of feminist theory and cognitive science, ed. R. Bluhm, A. Jacobson, and H. Maibom, 121-144. UK: Palgrave Macmillan.

12. Jordan-Young, Rebecca. 2010. Brain storm: The flaws in the science of sex differences. Cambridge: Harvard University Press. 